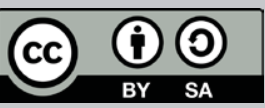

Loredo, E. (2021). Espacios de la movilidad cotidiana. Experiencias de los transeúntes. Collectivus. Revista de Ciencias Sociales, 8 (2), 111-136.

https://doi.org/10.15648/Collectivus.vol8num2.2021.3123

doi

\title{
STCOLECTIVLS
}

\section{Espacios de la movilidad cotidiana. Experiencias de los transeúntes.}

Espaces to daily mobility. Passerby experiences.

EdUARDO LOREDO GUZMÁN*

HTTPS://ORCID.ORG/0000-0003-1555-7680

* Doctor en Filosofía con Orientación en Arquitectura y Asuntos Urbanos. Facultad de Arquitectura, Subdivisión de posgrado. Universidad Autónoma de Nuevo León. Ciudad Universitaria. San Nicolás de los Garza, Nuevo León, México. C.P. 66451. Dirección de correo electrónico: loredox@gmail.com 


\section{RES U M E N}

En el siguiente trabajo se incorpora al estudio de la movilidad cotidiana desde el reconocimiento de experiencias y la relación con el espacio urbano. El debate sobre la movilidad cotidiana en la ciudad desprende varios frentes de análisis, refiere a una solicitud coyuntural de dinámicas urbanas en relación con los actores sociales; así mismo, propone una relación multidisciplinaria de enfoques teóricos- metodológicos para la argumentación de la realidad social contemporánea.

El presente documento de investigación implica una aportación desde un ángulo en el cual el espacio urbano es analizado acorde las experiencias que operan según las narraciones de los habitantes de la urbe en concordancia con la movilidad cotidiana. El espacio de observación será la ciudad de Monterrey, México.

Palabras clave: Movilidad cotidiana, Experiencias, espacios urbanos.

\section{A B S T R A C T}

The next paper is incorporated into the mobilility and daily living studies from recognizing experiences and the relation to the urban space. The debate on mobility in the city clearly shows different analyses; it refers to a conjunctural request of urban dynamics in relation to social actors. However, it proposes a theoretical and methodological multidisciplinary connection to argue about contemporary social reality.

This research involves another contribution towards an angle in which the urban space is analyzed according to the experiences from the narratives of the citizens according to mobility. The place of observation it is Monterrey, Mexico.

Keywords: Daily mobility, Experiences, urban spaces. 


\section{Des espaces à la mobilité quotidienne. Expériences des passants.}

\section{RÉ S U M É}

L'article suivant est intégré aux études sur la mobilité et la vie quotidienne à partir de la reconnaissance des expériences et de la relation à l'espace urbain. Le débat sur la mobilité en ville montre clairement des analyses différentes ; il renvoie à une demande conjoncturelle des dynamiques urbaines en relation avec les acteurs sociaux. Cependant, il propose une connexion multidisciplinaire théorique et méthodologique pour argumenter sur la réalité sociale contemporaine.

Cette recherche implique une autre contribution vers un angle dans lequel l'espace urbain est analysé selon les expériences des récits des citoyens selon la mobilité. Le lieu d'observation c'est Monterrey, Mexique.

Mots-clés: Mobilité quotidienne, Expériences, espaces urbains.

Espaços para a mobilidade diária. Experiências de transeuntes.

\section{RES U M O}

O próximo artigo é incorporado aos estudos da mobilidade e do cotidiano a partir do reconhecimento de experiências e da relação com o espaço urbano. $O$ debate sobre a mobilidade na cidade mostra claramente diferentes análises; trata-se de uma solicitação conjuntural da dinâmica urbana em relação aos atores sociais. No entanto, propõe uma articulação teórica e metodológica multidisciplinar para argumentar sobre a realidade social contemporânea. Esta pesquisa envolve mais uma contribuição para um ângulo em que o espaço urbano é analisado a partir das experiências das narrativas dos cidadãos em função da mobilidade. O local de observação é Monterrey, México.

Palavras chave: Mobilidade diária, Experiências, espaços urbanos. 



\section{Introducción}

La investigación que se propone acerca de la movilidad cotidiana en el área metropolitana de Monterrey implica la descripción de las dinámicas en el espacio, además de interpretar los elementos que ofrece las narrativas sobre el desplazamiento diario. A partir de esos principales componentes de análisis será factible abordar la construcción simbólica de la ciudad según sus habitantes.

Los habitantes de la ciudad dejarán de ser sujetos estáticos que el investigador ubica y determina según su lugar social. Bajo esta lógica de la movilidad la ciudad no está fragmentada en zonas de trabajo-camino-vivienda. Este camino requiere de la narrativa de los propios transeúntes porque "el camino soporta un proceso imaginario inevitablemente espontáneo." (García-García, 2015, 119) Es decir que se analiza con más interés a los medios que los fines. (Cisneros, et al, 2003)

En ese mismo orden de ideas se requiere replantear los proyectos que dotan de opciones para la movilidad cotidiana, explorar así las narrativas, es decir, las concepciones que responden a la complejidad para lograr cuestionar los diseños unilaterales que dejan de lado un enfoque participativo en el uso del espacio público.

Entre los objetivos de la presente disertación está el proponer una metodología de análisis de la movilidad cotidiana desde la perspectiva de las narrativas de los transeúntes para describir los significados del uso del transporte y la relación entre los espacios vividos de los habitantes de la ciudad. Con este acercamiento se pretende generar una 
plataforma argumentativa para el desarrollo de alternativas de movilidad y las dinámicas dentro de los habitáculos y espacios cercanos de las trayectorias cotidianas.

Para iniciar el acercamiento entre los constructos y la práctica, es preciso interpretar el fenómeno de la movilidad cotidiana desde los limítrofes de la objetividad y la subjetividad. El tipo de análisis es de corte cualitativo, auspiciado por un enfoque epistémico que cruza la relación espacial con la experiencia, donde las dinámicas de movilidad cotidiana se reconocen a través de las narrativas de los transeúntes.

Así mismo, se busca analizar la experiencia de la movilidad como forma de interaccionar con el espacio urbano en la vida cotidiana. La técnica para generar el acercamiento metodológico del estudio de la movilidad cotidiana en la ciudad de Monterrey serán las narrativas de la experiencia en loes espacios. "Más allá de la historia cuantitativa aparece, frágil y nueva, una geografía poética.” (Onfray, 2016, pág. 97) Las representaciones de la realidad a través de la perspectiva de los habitantes de la ciudad serán abordadas por medio de un análisis etnográfico para reflexionar las dinámicas de la vida cotidiana.

Esta investigación posibilitará la exploración y el análisis de la vida cotidiana desde la experiencia de la movilidad de los habitantes de la ciudad de Monterrey. El enfoque de estudio de la problemática urbana desde la fenomenología de la movilidad cotidiana recupera las propuestas sobre la conceptualización del "mundo de la vida" como eje operativo en la actividad de la producción en la vida social. La perspectiva espacial microsocial de la vida cotidiana enfatiza la relevancia de la comprensión desde las experiencias de los habitantes de la ciudad desde el estudio de "las vivencias espaciotemporales de los propios sujetos" (Lindón, 1997, pág. 180)

El transeúnte se rige por "las prisas, el ajetreo, la inquietud, los nervios y una angustia difusa que caracterizan la vida actual" (Han, 2015, pág. 53) Estos factores son justificantes para analizar la movilidad cotidiana entorno al tiempo y la experiencia del traslado. No sólo se trata de 
identificar el punto A hacia el punto B y la medición de su distancia y la temporalidad de traslado. Sino lo intermedio, el camino, sus medios, sus modos, sus discursos.

Para lograr formular un análisis oportuno es necesario recurrir a una serie de técnicas para recopilar la información y codificarla. Herramientas como la observación, (directa, participante), descripciones, -escribiría Geertz (2005, pág. 24) "la etnografía es descripción densa"- grupos focales, serán las adecuadas para rescatar las narrativas de la experiencia de la movilidad desde el "mundo de la vida cotidiana."

\section{Diseño metodológico}

El campo de acción de la movilidad cotidiana va más allá del supuesto pendular, aquel que indica el trayecto como una simple ida-vuelta, sino del proceso y el grado de las implicaciones sociales al propiciar la expansión de la mancha urbana. La vida cotidiana en la ciudad refiere a la movilidad como parte de su fenomenología; los usos del transporte para efectuar la movilidad, sin duda, ofrece el quid de las relaciones del individuo con la ciudad desde sus experiencias del trayecto, sus opciones para transportarse (según su capacidad económica) y la exclusión socioespacial.

La vida urbana adquiere un nuevo sentido en la medida de la exponencial relación con el movimiento, donde "la movilidad pone de manifiesto su capacidad de adaptación” (Duch, 2019, pág. 105). Las interacciones sociales se disipan en el espacio urbano, la especialización del espacio constituye el reto de lo presencial como entidad reguladora entre lo interno/externo.

En el 'estadio líquido' de la modernidad, la movilidad es el material con el que se construye una nueva jerarquía de poder, el factor primordial de estratificación, en tanto que la velocidad y la aceleración son las principales estrategias apuntadas a volcar ese factor en favor de uno. (Bauman, 2011, pág. 203)

Para Urry (2009) la movilidad es un fenómeno social y espacial, con la característica inusual que también incluye a los objetos, a la comunicación y las experiencias de los 
sujetos. Bajo este amplio concepto de movilidad se ejecuta el análisis a un nivel general, pero, según el autor, esto tiene como consecuencia la falta de un anclaje que favorezca la capacidad de descripción de los cambios en los fenómenos sociales actuales.

En este trabajo se suscribe la noción de movilidad conforme a la propuesta de una innovación en términos de construcción de un paradigma que define el estudio de los comportamientos de los individuos a través de los espacios vividos. Este análisis de la movilidad se soporta en la estrategia de concatenación de las pautas y los flujos socioespaciales acontecidos en la vida cotidiana.

El trabajo de campo consta de observaciones en sitios que se han detectado como puntos nodo de la movilidad cotidiana en la ZMM. Se efectuaron entrevistas semiestructuradas con informantes claves, principalmente usuarios habituales del transporte público. Además, se implementó la técnica de observación directa, la cual consiste en seguir a un itinerario de un usuario durante todo su trayecto desde su vivienda a su lugar de trabajo. La observación directa propone una recopilación de la experiencia de la movilidad desde una innovación metodológica en conjunto con la etnografía en movimiento (Jirón, 2012; Jirón y Imilan, 2016; Bolívar, 2017). Se realiza la etnografía desde el habitáculo de transporte y la cercanía con la dinámica de la movilidad permite detectar las estrategias y los "guiños» que vuelven extraordinaria la jornada cotidiana. La reflexión que surge sobre la base misma del movimiento no es cómo ni en cuál es el medio en que se mueven los transeúntes, sino qué sucede antes, durante y después de efectuar la movilidad como práctica cotidiana.

Dentro de este marco se amplía la noción de los escenarios de la movilidad como referentes espaciales móviles. Es bajo esta perspectiva que el significado de habitar la ciudad refiere a los ámbitos cotidianos visibles desde los recorridos, trayectorias, que se agrupan como parte de las habilidades del transeúnte en el efecto de cubrir sus necesidades de movilidad. 


\section{La movilidad y el espacio}

Se mencionaba líneas más arriba sobre el aspecto ritualizado de la movilidad cotidiana, el transeúnte se desplaza desde los bordes, cuida los detalles, se asegura de estar allí, aunque siempre se está pensando en otra cosa. Ir en el habitáculo viajando es como si fuera un umbral. "El umbral es una zona. Cambio, transición, mareas están en el término "umbral", y la etimología no ha de pasar por alto estos significados” (Benjamin, 2017, pág. 165) Viajar es habitar un espacio, es dejar a nuestro paso una breve señal de nuestro tránsito por la ciudad.

Se señalan los ritmos como sincronizaciones, y las rutinas como parte de los itinerarios. A decir de Marc Augé (1998) los itinerarios nos vinculan con nuestra historia, se escriben trazos de nuestra historia cotidiana que se vive en los habitáculos y las estaciones. "Cerca de los hospitales se encuentra siempre el puesto de un florista, una empresa de pompa fúnebres y una estación del metro” Por eso para hablar del metro se habla de cartografía y de lectura.

La forma de lectura es la propia narrativa. Se narra la experiencia en los espacios, desde el cómo son, hasta a qué huelen. "Los caminos del metro, como los del Señor, son impenetrables: uno no cesa de recorrerlos, pero toda esta agitación sólo cobra sentido a su término, en la sabiduría transitoriamente desencantada de una mirada retrospectiva” (Augé, 1998, pág. 21). Los espacios para la movilidad están diseñados para vivirlos en soledad. Cada obstáculo o travesía se hace a modo individual, se resuelven las conjeturas desde la intuición y la experiencia a modo de ser un transeúnte solitario en medio de una turba de gente.

Tienen recuerdos, costumbres, reconocen en él algunas caras y mantienen con el espacio de ciertas estaciones una especie de intimidad corporal que se puede medir por el ritmo de la bajada en el tramo de las escaleras, por la precisión del gesto que introduce el billete en la ranura de la puerta de acceso automático o por la aceleración de la marcha cuando se adivina por el oído la llegada del tren al andén. (Augé, 2010, pág. 38) 
Las infraestructuras son el primer contacto para el arranque de la movilidad. Las paradas de camión (parabuses) se encuentran en medio de la calle, interrumpen el tránsito de los peatones, se colocan en zonas donde algunas presentan dificultades dadas las diferencias en la altura del camión y las banquetas. Algunas paradas de camión presentan daños en su estructura, ya sea por actos vandálicos o por las inclemencias del tiempo, (como un ventarrón, o accidentes automovilísticos que derrumban parte del inmobiliario urbano de la movilidad). Desde punto de inicio el transeúnte se dispone al reto de moverse en la ciudad.

El transeúnte se acostumbra a esos espacios deficientes para la acción de la movilidad, es decir, "a medida que el espacio urbano se convierte en una mera función del movimiento, también es cada vez menos estimulante y más anodino. El conductor desea atravesar el espacio, no que este, a causa de su belleza o su extrañeza, atraiga su atención y movilice sus sentimientos” (Duch, 2019, pág. 63). En ese sentido mecanizado los espacio para la movilidad resultan un calco y copia de sí mismo, como si poco tuviera que aportar un espacio que marca un hito en la ciudad, son sólo montículos reproducidos en serie y con poco aporte estético.

\subsection{De la calle a los habitáculos de la movilidad.}

Los lugares se demarcan por ciertos límites, se configuran referencias que dejan una marca que el transeúnte reconoce, invoca como referencia y en ocasiones lo usa como guía para orientarse en el gran laberinto urbano. Estas marcas no son sino, como apunta Kevin Lynch (2015, pág. 92) hitos, "-puntos de referencia que se consideran exteriores al observador- son elementos físicos sencillos que pueden variar considerablemente de escala.” Esas marcas son útiles para el transeúnte al momento de identificar y diferenciar los lugares en sus trayectorias.

Estos hitos son marcas que no cuentan con el registro institucionalizado, la identificación de estas señas en el espacio se relaciona con la experiencia dentro de la dinámica de la movilidad. Una manera de acercarse a este conocimiento 
es por medio de las narrativas de la movilidad de los propios transeúntes. "Esta etnografía explora un cierto tipo de nodos urbanos desde conde dialogan los urbícolas con su ciudad." (Vergara, 2006, pág. 149) En este apartado, se recuperan las emociones, los conocimientos empíricos y las aproximaciones en que los transeúntes visualizan y reconocen el espacio en que se mueven cotidianamente.

En el caso de los habitáculos de la movilidad se pueden ceñir a los espacios en que se transportan los transeúntes, es decir, los vagones del metro, el interior de los camiones del transporte urbano. "Es, sobre todo, la movilidad moderna del tráfico de personas y mercancías la que ha creado condiciones de percepción y diseño radicalmente distintas para todo lo que se refiere al habitáculo humano" (Sloterdijk, 2018, pág. 385) Pero, si bien ese es el enlace espacial para definir un punto fijo en que se realizan dinámicas de la movilidad, también deben señalarse las acciones previas para acceder a ese espacio. Acá se hace referencia a las calles, a los puntos de embarque, a los trayectos (la mayoría de las veces) realizados a pie, esos territorios que debe ser cruzados cotidianamente para acoplar las adinámicas propias del acto de movilidad.

Entonces antes de describir los habitáculos, habría que considerar lo que ocurre en la calle como parte de la movilidad cotidiana. La calle es parte del umbral, es un espacio transitorio. "En el crucero de las calles se vive una emoción, la sangre refluye como en un corazón inquieto, la metáfora se convierte así en una realidad íntima” (Bachelard, 2014, pág. 245) En las calles no sólo se transita de modo mecánico, es ante todo un espacio político, un lugar que cada transeúnte inscribe según su experiencia concreta. La calle es este concepto amplio que denota el espacio abierto, la libre andanza por la ciudad desde que se sale de casa y se busca otro refugio.

Según Simmel (2013) la ciudad encuentra su ritmo en las calles, se muestran dimensiones y apariencias de las actividades que son intermediarias de la imagen urbana. Los transeúntes, en este caso los entrevistados, enseguida refieren a la calle como el espacio que se convierte en el

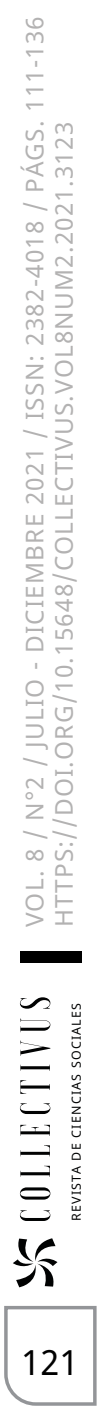


nodo para efectuar sus trayectorias. De esas prácticas cotidiana de la movilidad se expresan elementos narrativos que describen cómo las dinámicas sucesivas de la movilidad inician y concluyen en la calle. Los procesos del caminante son, para De Certeau (2007), un registro de los pasos a medida que narran sus trayectorias.

Los entrevistados refieren a una cercanía y familiaridad con las calles que han sido parte de sus trayectorias cotidianas, suelen ser seguras en medida que se marcan en un radio aledaño a su vivienda. Pero, también se indica que ese reconocimiento del espacio los ayuda a sortear las situaciones adversas y eventualidades que se pueden presentar en las calles. Cruzar baldíos, calles oscuras, franquear parques son algunas de las relaciones que se tienen con este acto de enlace durante la movilidad cotidiana. Aunque las mujeres refirieron la situación de deterioro en el servicio de alumbrado público como un factor de inseguridad, al grado de tener que ser acompañadas por un familiar, la mayoría de las veces por un varón.

Estas aventuras narradas, que de una sola vez producen geografías de acciones y derivan hacia los lugares comunes de un orden, no constituyen solamente un "suplemento" de las enunciaciones peatonales y las retoricas caminantes. En realidad, organizan los andares. Hacen el viaje, antes o al mismo tiempo que los pies lo ejecutan. (De Certeau, 2007, pág. 128)

En los actos de caminar, de recorrer las calles también se involucra el preámbulo del ritmo. El tiempo es también es un factor de confianza, pues, el transeúnte sabe por cuáles caminos recorrer según la hora del día, el clima o las coyunturas que se presentan en el entorno. Aunque en ocasiones sea breve el paso de la vivienda hasta la parada del camión o la estación del metro, ese tiempo se contabiliza dentro de sus trayectorias

La confianza en la reconfortante seguridad de las calles urbanas destila de la multitud de encuentros y contactos mínimos que surgen en sus veredas. El sedimento y el rastro perdurable que dejan los contactos públicos casuales forman un entramado de comunión-en-lo-público, tejido con los hilos del respeto y la confianza de la civilidad. (Bauman, 2015, pág. 97) 
Las calles que se transitan para iniciar o finalizar la movilidad cotidiana resultan los espacios de familiaridad, se define en este trayecto el ánimo en que se inicia o concluye el recorrido habitual por la ciudad. "El vacío del lugar está en el ojo de quien lo contempla y en las piernas del habitante o en las ruedas de su auto.” (Bauman, 2017, pág. 113) No sólo se presentan como vías de paso, sino que se enlazan con otras actividades que cubren nuestras dinámicas urbanas, por ejemplo, en la calle como umbral se pueden localizar vendedores ambulantes, se compra el periódico, un cigarro, dulces, se puede solicitar "feriar" (sic) un billete de baja denominación para pagar el importe exacto del costo del viaje.

La experiencia de una calle la establece la relación entre los peatones y los vehículos. Durante gran parte del siglo $\mathrm{XX}$, el tejido urbano se reconfiguró para el coche, con un impacto gravemente negativo para la vida tradicional de las calles. Las calles reflejan las raíces y las historias de las ciudades. (Sudjic, 2018, pág. 86)

Se indicaba anteriormente que la experiencia de la calle también se refleja en un conocimiento de la calle, quizá mejor explicado en un reconocimiento, un "saber de la calle” en donde es plausible la identificación con los otros según ciertos códigos, como un saludo cordial, una mirada precisa sin llegar a ser intimidante o el simple ritmo en que se debe transitar por la vereda. (Sennett, 2019, pág. 224) "Las calles proponen o imponen recorridos. Están abiertas para y no por el desplazamiento” (Nancy, 2013, pág. 110). Estos trayectos muchas veces dominados por los transeúntes son sus referentes de seguridad y confianza, se pueden establecer las relaciones que tienen con las calles de su barrio, algunos refieren que esta complicidad los atrae a caminar por las calles más iluminadas, o donde "hay más vida", para luego encontrarse con la fracción del recorrido que se experimenta de manera más solitaria. (Le Breton, 2016; Masagualli y Bolaño, 2017) Así mismo, se puede considerar que, las calles son también ese umbral que nos prepara para nuestro arribo a los habitáculos de la ciudad. 
Figura 1. Ritmos de la ciudad en los espacios de conexión. Afuera de la estación Asarco de la Ecovía. (BRT)

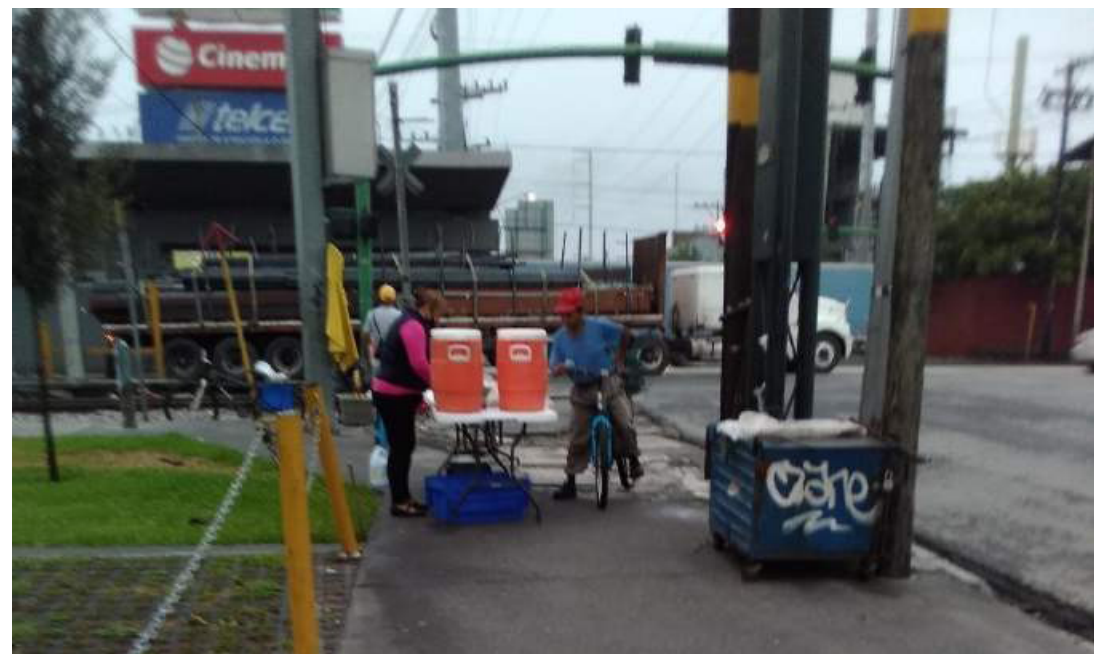

Fuente: Syndy Sánchez.

Figura 2. Puestos de comida callejera en las inmediaciones de la Estación Padre Mier, Línea 2 del metro

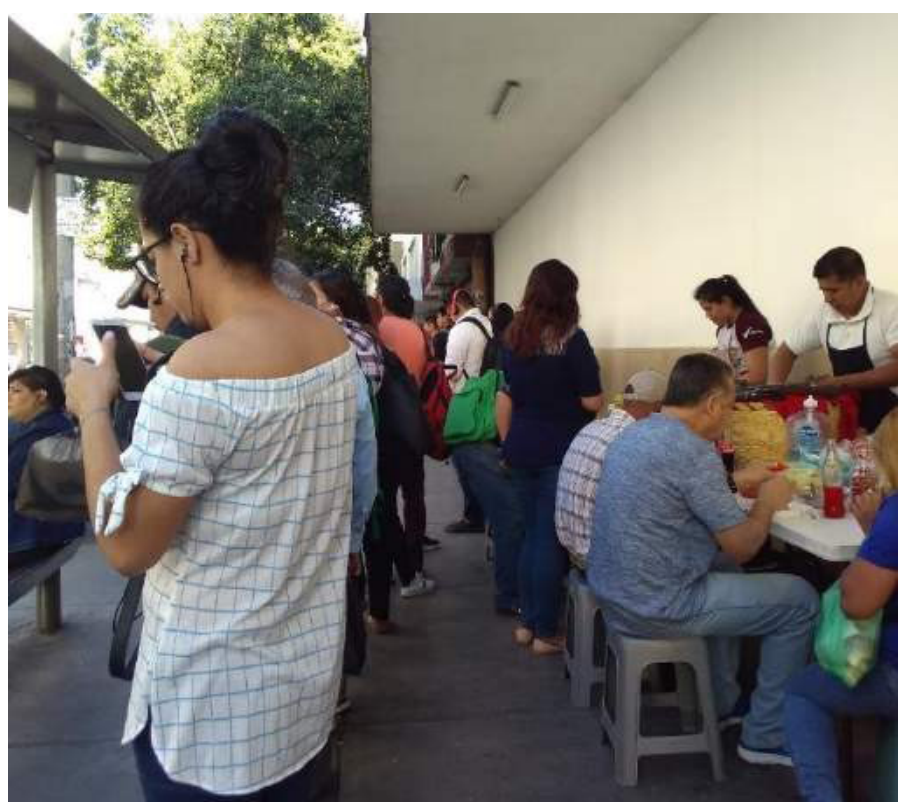

Fuente: Syndy Sánchez. 


\section{Micro universo de los habitáculos}

En ese trayecto de la calle hasta los habitáculos se realizan actos diversos; en el caso de caminar, el transeúnte debe estar atento a su entorno, las referencias narrativas sobre la experiencia de la movilidad cotidiana apuntalan a una manera de andar en la calle con miras a diferenciar los procesos que pueden interferir o mejorar la dinámica, pero, con relación al habitáculo se describe una experiencia ligada a los otros. Esto último es de interés para comprender las vivencias en los espacios enfocados al traslado, pues son estos recintos donde se presentan muchas de las dinámicas que configuran el catálogo de experiencias sensoriales de la movilidad.

Lejos de poder hacer una contribución unívoca en el ámbito de las emociones y sensaciones se busca dar pie a las evocaciones, remembranzas, experiencias de aspectos subjetivos que subrayan cómo se siente y cómo se vive la dinámica de la movilidad cotidiana desde los habitáculos. Por experiencia en el habitáculo se entiende esa reconstrucción del fenómeno del espacio desde sus características física, pero, en función de las relaciones que factura al individuo con los otros desde una percepción (sensual) de lo acontecido durante ese lapso en que se cohabita. (Sloterdijk, 2018; Bossio, 2019) Este análisis situado en los espacios establecidos para realizar el viaje como el interior de los vagones del metro, de los vehículos motorizados y de los camiones del transporte urbano es a la vez una reseña de las condiciones en que se viaja y cómo se manifiesta en los sentidos del transeúnte.

La experiencia es un punto clave en las narraciones sobre la movilidad cotidiana, se narra compaginando un análisis de las formas de sensibilidad que surgen en el acto de moverse a través de la ciudad. "[Los] habitáculos ofrecen ocasiones de proximidad, incluso de promiscuidad, que fuerzan a la relación u obliga a la conversación. En ese microcosmos comunitario tiene lugar una intersubjetividad limitada en el tiempo" (Onfray, 2016, pág. 42). En el habitáculo la presencia del ritmo hace factible la comprensión, en mayor o menor medida de las relaciones sensoriales, se aprende a ubicarse como individuo frente a la colectividad, pero sin dejar rastro de presencia. 
Este ejemplo sea útil para colocar la reflexión sobre los habitáculos como un proceso de incorporación al ritmo de una urbe. En otra oportunidad Benjamin con un tono introspectivo comparte al lector este pensamiento sobre el metro:

¿Quién no habrá salido alguna vez del metro al aire libre sin haberse sentido impresionado por entrar en la luz del sol? Y sin embargo unos minutos antes, cuando bajábamos por las escaleras, ese Sol ya brillaba con el mismo resplandor. De ese modo con tanta rapidez olvidamos el tiempo que está haciendo en el mundo de arriba, y con igual rapidez nos va olvidando a nosotros el mundo. (Benjamin, 2011, pág. 83)

Este relato se vincula a los sentidos. Se aproxima a una noción de verse inmiscuido en una experiencia que desea compartir a modo de saberse como otro más de los cientos de miles que efectúan cotidianamente el acto de la movilidad y de habitar sus espacios. Son los recorridos un punto en encuentro entre los espacios públicos, que la mayoría de las veces se colocan en una característica abierta, pero, los habitáculos de la movilidad son precisamente lugares públicos cerrados, que cotidianamente son frecuentados por los transeúntes, aunque sea en modo efímero.

Cuando los entrevistados relataban (muy a su modo) sus mapas mentales, estos chocaban con las ideas de ordenamiento geográfico, pues se desprendían narrativas que se asociaban con los lugares y su experiencia. Esto sin duda es claro ejemplo de la acumulación de espacios vividos trascendentales que han acopiado a lo largo de su historia como transeúntes en la ciudad (Salvatori y Terrón, 2019). La mayoría de los entrevistados realizó este ejercicio a manera de relación con los sentidos y sus recuerdos estaban ligados a momentos importantes en su vida, señalaron sus puntos de residencia, los lugares de trabajo, los recintos educativos y ese todo era precisamente el mapa mental que ampliaba su noción de trayectoria a manera de comprender la movilidad cotidiana como un proceso continuo y dinámico. 


\section{La experiencia de los espacios a través de los sentidos}

George Simmel (2014) inicia su exposición de un breve ensayo sobre la sociología de los sentidos con la tonalidad de la voz, ese rasgo que distingue la amabilidad, la cercanía o la jerarquía de quién habla. El timbre y el tono de la voz es nuestra primera carta de presentación. En los espacios se asume -de manera tácita- la tonalidad en la cual nos comunicamos, es decir, en un ámbito donde una autoridad está hablando se susurra, al igual que los recintos religiosos se busca lo menos interrumpir a los demás. En cambio, en alguna actividad recreativa o de disfrute es notorio como las personas alzan la voz sin que esto suela sentirse como una transgresión.

La voz de una persona nos produce un afecto atractivo o repulsivo, diga lo que diga; Lo propio ocurre con las impresiones de los sentidos; penetran en el sujeto en la forma de sentimiento y estado de ánimo, pero conducen hacia el objeto en la forma de conocimiento. (Simmel, 2014, pág. 622)

En el caso de los habitáculos -como en el metro o en el camión, las conversaciones son dispares, se pueden escuchar las conversaciones de los jóvenes con un tono de algarabía, esto pocas veces es interrumpido por otros, pero, también se logran percibir los cuchicheos de las parejas, es un pacto de complicidad.

Por lo general, según los entrevistados, se debe gritar para "pedir una bajada", es decir, cuando el viajero solicita descender del camión muchas veces lo debe hacer con autoridad, con un tono de enojo. Posiblemente no sea por una falta de respeto hacia el chofer, sino que se trata de ser escuchado, o bien es un tono de reclamo. A decir de Miner$v a$, (conversación personal) una entrevistada, enfermera de 37 años, que relataba cómo se rompe el silencio en el metro porque "siempre es cuando invaden tu espacio personal, todo va bien, pero algunos te empujan o no te dejan salir en una estación y debes hablar fuerte. Yo no soy enojona, pero si me doy cuenta como que mi voz es otra, con muchas ganas... pero 
sólo es un "con permiso" o "me das chance (sic) de pasar", no creas que les digo algo malo, o feo, pero si con mucha fuerza. No se toma a mal, es más como que así es, porque si ya de plano no te escucha pues le tocas el hombro o de plano lo empujas, pero casi en el metro es más de decirlo fuerte, no gritando. Como, sabes dónde sí se debe gritar, en el camión, allí sí no te escucha el chofer no te bajan y luego te toca caminar más.”

Como mencionaba la entrevistada acerca del espacio personal, son precisas las dimensiones de la distancia, esta distancia marca el espacio corporal frente a los otros, muchas veces en "hora pico" los camiones lucen repletos, los vagones del metro están saturados y difícilmente se respeta la mínima distancia, se llega a tener contacto con otros de manera fortuita, pero con el entendimiento que es una eventualidad. Acerca de este punto, relataba Luís, estudiante y trabajador de 23 años, narra cómo es ir siempre en hora pico: Es desde que entras ir empujando a la banda, y a medio que te haces un lugar pues vas como cuidándote siempre, sientes como te rozan el pantalón y te pones alerta para sentir la cartera o de volada (sic) [rápido] palmas el celular. Se siente gacho ir como apretado, sientes... bueno la neta es que los puedes oler, como es de mañana pues la mayoría huele a limpio, pero no falta aquel que tiene un humor pesado [olor fuerte], porque por lo mismo, para las 9 de la mañana ya hace calor y más allí en el camión todos apretados, empiezas a sudar. Es como una experiencia de olores muy mezclada, porque también en el camión puedes oler a las chavas que se van arreglando [maquillando] y como casi las mujeres son las que van sentadas pues puedes oler el cabello húmedo, todavía a champú. (...) pero en la tarde, ya se mezclan todos los olores, es igual en verano que en frío [invierno], porque en invierno como no prenden el clima [calefacción] se encierra bien gacho el aroma de todos. Es que a veces si como que se me olvida, pero, también te pasan cosas curadas [graciosas], una vez yo estaba en el metro y una viejita [Mujer adulto mayor]olía como mi abuelita, hasta me acerqué para olerla, fue como un recuerdo muy bonito.

También es puntual rescatar una pequeña aportación que realizó un entrevistado que mencionaba que él era capaz de detectar algunos lugares en la ciudad por los 
olores, indicó que en ocasiones cuando se quedaba dormido en el camión podía reconocer la ubicación según el olor que se desprende principalmente de algunas fábricas. Es fácil saber que cuando huele a galletas estás por acá, cuando viví por "el pedre" [pedregal de Escobedo] en las mañanitas como húmedas, en la parada del camión olía a la huesera. También por cervecería huele a "confleis" [cereal] y cuando huele así gacho, es la curva esa de [la avenida] Miguel Alemán.

Estos registros aromáticos contribuyen también a un distingo de los sujetos en relación con el espacio, son marcas en la ciudad. Las calles se llenan de aromas, se entremezclan los olores de aceite recalentado en los puestos de comida callejera con los charcos permanentes los linderos de las banquetas. "La cuestión social no es sólo una cuestión moral, sino también una cuestión nasal” (Simmel, 2014, pág. 631). Se detecta en el aroma una distinción, es una presentación del viajero frente a los otros; en las calles a pocos pasos se pierden los aromas fabriles y se cruzan otros aromas forzados por la higiene y limpieza de algunos comercios. (Dupey y Pinzón, 2020; Esteban, Amador, Mateos y Olmedo, 2019)

Así como el olfato confiere de un registro de remembranza, el tacto en los habitáculos es tema de debate sensible, aunque igualmente desde la mirada se hace una primera aproximación a ese contacto con el otro. La mirada también irrumpe en el espacio personal, se invade al otro con una mirada que delata intenciones y juicios. En los habitáculos de la movilidad los transeúntes ejercen una suerte de ausencia, no quieren estar, su mirada refleja ese enfoque al vacío, a un punto fijo que no trastoque la relación con los otros.

Cuando se realizó el trabajo de campo se detectó esta situación de la mirada pérdida. Ponerse a ver cómo y qué ven los transeúntes durante el viaje suele ser un acto lleno de matices. "La más mínima desviación, el más ligero apartamiento de la mirada, destruye por completo la peculiaridad del lazo que crea” (Simmel, 2014, pág. 623) Todos se cuidan de no ser vistos, ni de ver demasiado a alguien; la escena es casi como el cuadro de Las meninas de Velázquez. Ver cómo otro ve a otro y seguramente alguien ve a ese primero que ve a los 
otros verse. Esto es sin que cada uno de los participantes en esta observación detecte que lo observan. Cuando las miradas cruzan se debe ser firme sobre lo que se observa.

Por ejemplo, un joven estudiante contaba que uno de sus pasatiempos mientras viajaba era ver los tenis de los demás, era casi como una fijación de ver el calzado o algunos atuendos tanto de hombres como de mujeres. Eso le traía algunos problemas porque en ocasiones las mujeres detectaban su mirada y él sólo trataba de esbozar una sonrisa que lo disculpara.

Pero en efecto, las mujeres sufren mucho al ser observadas por los hombres en el transporte público. Bárbara, 27 años, vendedora por cuenta propia, hace la mayoría de las entregas de su mercancía en las estaciones del metro. Me toca que a veces me tengo que esperar a que llegué la chica a quien voy a entregar la ropa y así, y todos los chavos están de viborones (sic)[observadores]. Ni creas que siempre ando muy arreglada, pero eso no importa, te ven, o sea te están como observando mucho... no sé, hasta me ha pasado que ni se suben en el metro por seguirme viendo. O también me toca ver cómo ven a otras chicas no sé cómo de que me dan asco. Algunas veces si medio me pongo a decirles cosas, como que “¿qué ves? ¿se te perdió algo?”y como que les da vergüenzay se van o dejan de verme, pero eso pasa mucho en el metro que todos los chavos te están viendo o hasta escuchando cuando vas hablando por teléfono y así. Algunos hasta se ponen a lado mío para leer mis mensajitos del cel. (risas).

En comparación con la ciudad pequeña, el tráfico de la gran ciudad se basa mucho más en el ver que en el oír, la razón de ello no es sólo que en la ciudad pequeña las personas que nos encontramos en la calle son, con frecuencia, conocidos, con quienes cambiamos unas palabras o cuya visión evoca en nosotros su personalidad total además de la visible, sino, sobre todo, por causa de los medios de comunicación públicos. (Simmel, 2014, pág. 626)

En los habitáculos de la movilidad difícilmente se puede mencionar como un espacio íntimo, porque el transeúnte está a la vista de todos. Un joven señalaba, que por traer el cabello largo y vestir de cierta forma extravagante, la gente 
no dejaba de verlo, con miradas que lo delataban culpable. De qué, no se sabe bien. Pero las miradas en estos espacios suelen llevar un juicio ambiguo. De alguna forma el contacto es la ruptura completa con cierto orden sensorial. El contacto es prohibido según las reglas no escritas, por ejemplo, hasta para ayudar a alguien a subir al camión o abrirle paso, se debe advertir que le tomarás la mano, o que lo rodearás con el cuerpo.

Cuando se debe interrumpir a alguien, o realizar algún señalamiento sólo se le toca el hombro con un solo dedo que si acaso llega a tener un contacto muy leve con el otro. En los habitáculos del camión del transporte público, los asientos que están en dirección a la ventana muchas veces no se ocupan en primera instancia porque entra mayor luz, calor o en los camiones climatizados es ese punto donde se dirige el aire acondicionado, por lo que es común que se deba solicitar permiso para acceder a esos asientos y se tiene un contacto con las piernas, algunos, si hay espacio, deciden levantarse del asiento y dejar que libremente el otro viajero tome su lugar cerca de la ventana. Esto se realiza con el afán de evitar siempre un contacto innecesario.

\section{Figura 3. Sin espacio. Habitáculo del metro Línea 2 Estación Tapia}

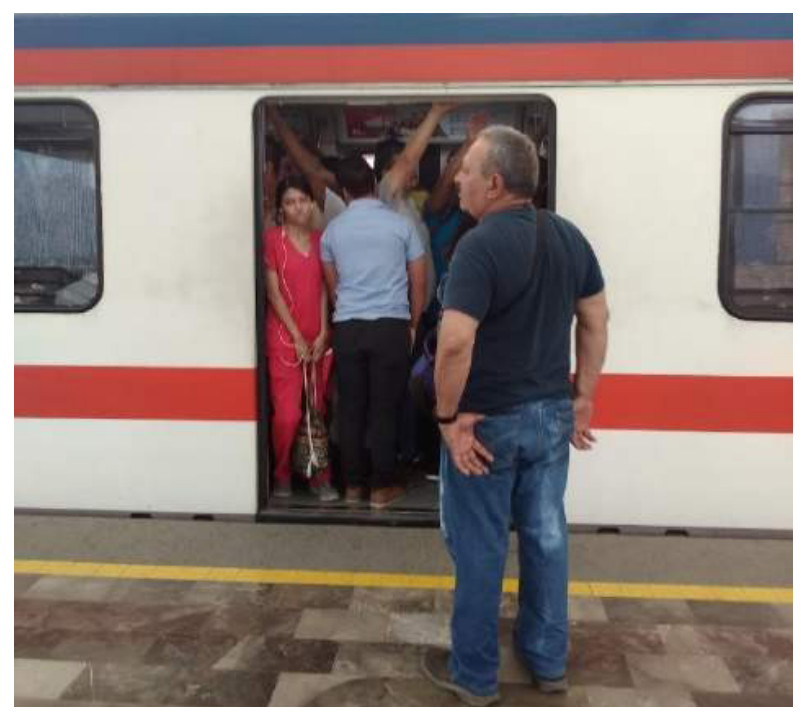

Fuente: Syndy Sánchez. 
Figura 4. Sin contacto visual. Habitáculo del metro Línea 1 Estación Anaya

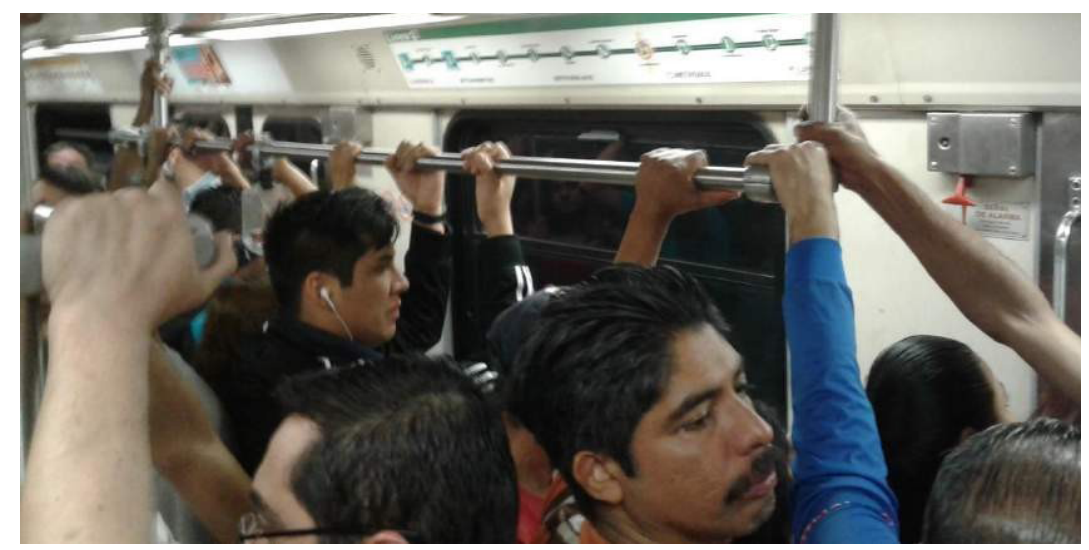

Fuente: Eduardo Loredo.

\section{A modo de cierre}

En el entramado de espacios que invisten a los habitáculos usados en los trayectos se tropiezan todos los sentidos para descifrar el fenómeno de la movilidad. Estos aspectos casi imperceptibles y poco analizados dentro de los estudios de la movilidad urbana son de suma importancia para comprender las consideraciones subjetivas e intersubjetivas que se asocian a las dinámicas cotidianas. Un aporte de análisis fenomenológico que va más allá de las consideradas variables “objetivas” debe incorporar en sus marcos de referencia las implicaciones de los sentidos como parte de la perspectiva de observación.

Es un mundo de cultura porque desde el comienzo el mundo de la vida es un universo de significación para nosotros, es decir, una estructura de sentido (Sinnzusammenhang) que debemos interpretar, y de interrelaciones de sentido que instituimos sólo mediante nuestra acción en este mundo de la vida. (Schutz, 2003, p.137)

Las formas de sensibilidad es un tema que se emplea a modo de conocer los vericuetos de la socialización, se pautan reglas no escritas, se pisa en terreno de intuiciones y se 
responde de manera racional a una serie de experiencias que describen cómo se viven las dinámicas urbanas como la movilidad. Qué sucede a nivel microsocial en esos espacios trashumantes, cómo se vive la experiencia en un sitio repleto de personas “desconocidas”, cuáles son las estrategias para sobrellevar situaciones que pueden considerarse al límite de la sociabilidad espaciotemporal.

En este punto se recuperan los hallazgos sobre lo no dicho, lo que escapa a una enunciación o carece de un cuadrante que lo module de forma generalizada. En el análisis estructural de los signos lingüísticos se inscribe un apartado que con mucho esfuerzo logra ser transmitido, su comprensión no permanece estática como suelen ser los formatos de codificación del habla, sino suele ser un terreno más profundo, donde los gestos, las distancias y las miradas son cómplices de un mensaje encriptado. "No cabe duda de que ciertos gestos son convencionales; pero la mayoría son espontáneos y, si no son universales, por lo menos están muy generalizados, mientras que todas las palabras se hallan rigurosamente codificadas” (Guiraud, 2018, pág. 83) En los gestos está otro lenguaje. Quiénes lo describen ven en otros sus reacciones, la experiencia es compartida pero no por eso es idéntica o se acoplan a una interpretación nominal.

Este ejercicio de narración de parte de los transeúntes con sus dotes de expertos acerca de la movilidad cotidiana en la ciudad es también una tarea de descifrar los signos que en la ciudad se muestran. Un poco se asume a las premisas expuestos por Italo Calvino que postula que "La ciudad es siempre transmisión de mensajes, es siempre discurso, pero una cosa es si este discurso debes interpretarlo tú, traducirlo tú en pensamientos y palabras, y otra si estas palabras te son impuestas sin escapatoria posible” (Calvino, 2002, pág. 119). Hay mensajes, discursos y signos que sólo quién habita y de la forma en qué lo hace logra interpretar, pues, es únicamente desde la experiencia en eso que osamos en llamar vida cotidiana que no es otra situación que el cúmulo de actividades que se deben lidiar para cumplir con los roles sociales. En este sentido, la recuperación de las narrativas son precisamente el rasgo señero de la labor por interpretar su realidad a partir de su experiencia a nivel sensorial. 


\section{Referencias bibliográficas}

Augé, M. (1998) El viajero subterráneo. Un etnólogo en el metro. Barcelona: Editorial Gedisa.

Augé, M. (2010) El metro revisitado. El viajero subterráneo veinte años después. Barcelona: Editorial Paidós.

Bachelard, G. (2014) La tierra y las ensoñaciones del reposo. México DF: Fondo de Cultura Económica.

Bauman, Z. (2011) La sociedad sitiada. México DF: Fondo de Cultura Económica. Bauman, Z. (2015) Daños colaterales. México DF: Fondo de Cultura Económica. Bauman, Z. (2017) Modernidad líquida. México DF: Fondo de Cultura Económica. Benjamin, W. (2011) Calle con dirección única. Madrid: Abada Editores.

Bolívar, D. (2017). Convivencia ciudadana versus narciso: La batalla por un orden civil pacífico e igualitario. Collectivus, Revista de Ciencias Sociales, 4(1), 126-154. https://doi. org/10.15648/Coll.1.2017.7

Bossio, V. (2019). “iMe caso y me voy!”: migraciones transnacionales femeninas desde el Caribe hispánico hacia Italia. Collectivus, Revista de Ciencias Sociales, 6(1), 135-154. https://doi.org/10.15648/Coll.1.2019.8

Calvino, I. (2002). Colección de arena. Madrid: Editorial Siruela.

Cisneros A., Esquivel M. y Huarte, M. (Coords.). (2003) Cómo mirar la ciudad. México DF: Universidad Autónoma Metropolitana-Azcapotzalco.

De Certeau, M. (2007) La invención de lo cotidiano. Tomo 1. Guadalajara: Universidad Iberoamericana- ITESO

Duch, LL. (2019). Vida cotidiana y velocidad. Barcelona: Editorial Herder.

Esteban, M., Amador, L., Mateos, F., y Olmedo, F. (2019). Mujer y medio ambiente. Una aproximación desde la acción socioeducativa. Collectivus, Revista de Ciencias Sociales, 6(1), 177-195. https://doi.org/10.15648/Coll.1.2019.10

García-García, A. (2015) La carretera como camino en su contexto territorial. En Osuna, J F. y Aragón Palacios, M. (Ed.) Estudios urbanos: una mirada desde la transdiciplina, (págs. 119-130) Monterrey: UANL-Tilde editores. 
Geertz, C. (2005) La interpretación de las culturas. Barcelona. Editorial Gedisa.

Guiraud, P. (2018) El lenguaje del cuerpo. México DF: Fondo de Cultura Económica

Han, B. (2015) El aroma del tiempo. Un ensayo filosófico sobre el arte de demorarse. Barcelona: Editorial Herder.

Jirón, P. (2012) Transformándome en la sombra. Bifurcaciones. Revista de Estudios Culturales Urbanos 10: 1-14.

Jirón, P., y Imilan, W. (2016). Observando juntos en movimiento: posibilidades, desafíos o encrucijadas de una etnografía colectiva. Alteridades, 26 (52), 51-64.

Le Breton, D. (2016) Desaparecer de sí. Una tentación contemporánea. Madrid: Editorial Siruela.

Lindón, A. (1997). El trabajo y la vida cotidiana. Un enfoque desde los espacios de vida. Economía y Sociedad, 1: 177-197.

Lynch, K. (2015). La imagen de la ciudad. Barcelona: Gustavo Gili Editores.

Masagualli, N., y Bolaño, O. (2017). Alternativas de poder político en los movimientos sociales-rurales de Colombia: caso organización indígena del norte del Cauca. Collectivus, Revista de Ciencias Sociales, 4(2), 36-54. https://doi. org/10.15648/Coll.2.2017.3

Nancy, L. (2013) La ciudad a lo lejos. Buenos Aires: Ediciones Manantial.

Onfray, M. (2016) Teoría del viaje. Poética de la geografía. México DF: Editorial Taurus.

Salvatori, S., y Terrón, T. (2019). L’approccio intersezionale e quello transnazioanle nello studio dei flussi migratori: elementi per una proposta analitica. Collectivus, Revista de Ciencias Sociales, 6(1), 35-46. https://doi.org/10.15648/ Coll.1.2019.3

Schutz, A. (2003) El problema de la realidad social. Buenos Aires: Amorrortu. Sennett, R. (2019) Construir y habitar. Ética para la ciudad. Barcelona: Editorial Anagrama.

Simmel, G. (2013). Roma, Florencia, Venecia. Madrid: Editorial Casimiro 
Simmel, G. (2014). Sociología: estudios sobre las formas de socialización. México DF: Fondo de Cultura Económica.

Sloterdijk, P. (2018). Esferas III. Madrid: Editorial Siruela.

Urry, J. (2019) Mobilities. Cambridge: Polity Press.

Vergara, A. (2006). Espacio, lugar y ciudad: etnografía de un parque. En Lindón, A, Aguilar, M. y Hiernaux, D. Lugares e imaginarios en la metrópolis. México DF: Editorial Anthropos- UAM I. 